\title{
STRUCTURAL ANALYSIS ON COMPOSITE LAMINATE WITH
}

\section{DIFFERENT ORIENTATION}

\section{B. NIHARIKA ${ }^{1}$, N. MADHAVI ${ }^{2} \&$ M. SAI KRISHNA ${ }^{3}$}

${ }^{I}$ Assistant Professor, Department of Aeronautical Engineering, MLR Institute of Technology, Hyderabad, Telangana, India

${ }^{2}$ Associate Professor, Department of Aeronautical Engineering, MLR Institute of Technology, Hyderabad, Telangana, India

${ }^{3}$ B. Tech Student, Department of Aeronautical Engineering, MLR Institute of Technology, Hyderabad, Telangana,India

ABSTRACT
The aim of the project is to analyze the structural analysis on a composite plate with different orientation, with
the same material properties. A composite material consists of two or several material.
A composite laminate of cantilever beam was designed and fabricated using graphite epoxy for structural
mechanics behavior. Two design cases $\{[0 / 90 / 0 / 90]$, [0/45/0/45]\} of different orientations of composite laminate were
laminate of cantilever beam was performed by applying load conditions.
KEYWORDS: Composite, Ply Orientation, Positions Ratio \& Young's Modulus

Received: Nov 20, 2017; Accepted: Dec 11, 2017; Published: Jan 12, 2018; Paper Id.: IJMPERDFEB201861

\section{INTRODUCTION}

Composites are made up of two or several materials with same or different physical or chemical properties. It produces a material with different properties, which is different from individual material. The composites are the stronger, lighter and cost less. These are having high applications, as compared with traditional materials with properties.

\section{Classification of Composites}

The Classification is based on geometry of reinforcement and type of matrix. Geometry based reinforcement composites are particular, flake, fiber composites. These are represented in the following figures.

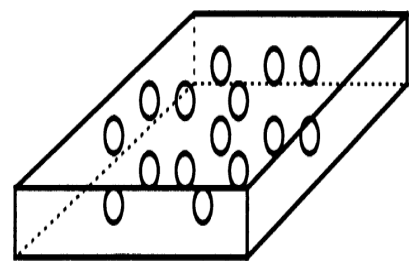

a) Particular composite

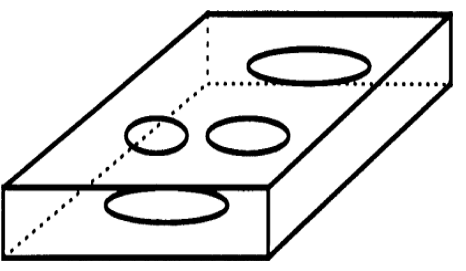

b) Flake composites

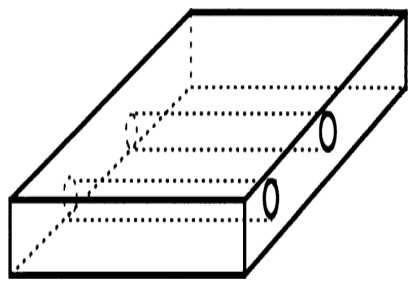

c) Fiber composites

Matrix type based composites are polymer matrix, metal matrix, carbon-carbon, graphite Epoxy. In this project, we are considering a cantilever beam with two different orientations for the same laminates by using ANSY16.0 


\section{FINITE ELEMENT METHOD}

FEM will give the approximate solution for the given problem. It is suitable for boundary value problems. These problems consist of partial differential equations (PDE), and boundary conditions. By using FEM, we can convert the elliptical differential equation into algebraic equations. To solve the problem in fem, it subdivides a large problem into smaller problems. These problems are known as finite elements. The problem can be solved in three steps as pre-processor, post processor, solution.

The various types of Fem methods are aem, gfem,mfem,xfem,sem.

\section{PROBLEM DEFINITION}

Determine the best orientation among 45 degrees (or) 90 degrees in Graphite/Epoxy symmetry laminate of 8 layers. We take laminate as a cantilever beam, condition under load of $8000 \mathrm{~N}$, applying at free end of cantilever beam through the structural analysis in ANSYS 16.0. In this, we are discussing voin mises stresses in different ply orientation angles.

Table 1: Material Properties

\begin{tabular}{|c|c|c|c|}
\hline $\begin{array}{c}\text { Young's } \\
\text { Modulus }\end{array}$ & Poisions Ratio & Shear stress & Density \\
\hline $\mathrm{EX}=1.81 \mathrm{E}+011$ & $\mathrm{PRXY}=0.28$ & $\mathrm{GXY}=7.17 \mathrm{E}+009$ & $1620 \mathrm{Kg} / \mathrm{m}^{3}$ \\
\hline $\mathrm{EY}=1.03 \mathrm{E}+010$ & $\mathrm{PRYZ}=0.6$ & $\mathrm{GYZ}=3 \mathrm{E}+009$ & \\
\hline $\mathrm{EZ}=1.03 \mathrm{E}+010$ & $\mathrm{PRXZ}=0.27$ & $\mathrm{GXZ}=7 \mathrm{E}+009$ & \\
\hline
\end{tabular}

In the ply orientation, the symmetric layers are considered in both orientations.

Table 2: Ply Orientation in Different Angles

\begin{tabular}{|c|c|c|c|c|c|}
\hline \multicolumn{3}{|c|}{ Case-I (ply orientation $\mathbf{9 0}^{\mathbf{0}}$ ) } & \multicolumn{3}{c|}{ Case-II (ply orientation $\mathbf{4 5}^{\mathbf{0}}$ ) } \\
\hline Layers & Thickness(m) & Orientation & Layers & Thickness(m) & Orientation \\
\hline 1 & 0.001 & 0 & 1 & 0.001 & 0 \\
\hline 2 & 0.001 & 90 & 2 & 0.001 & 45 \\
\hline 3 & 0.001 & 0 & 3 & 0.001 & 0 \\
\hline 4 & 0.001 & 90 & 4 & 0.001 & 45 \\
\hline
\end{tabular}

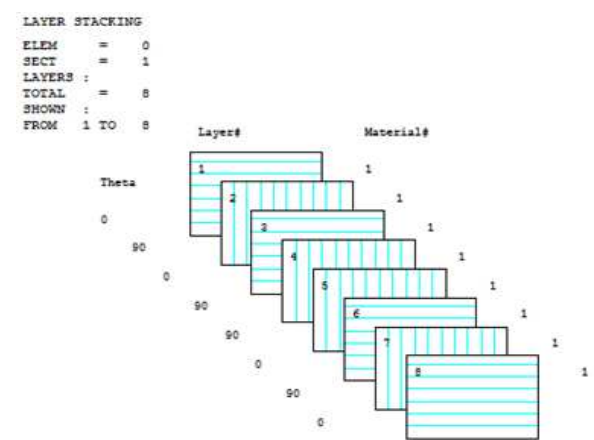

Figure 1: Ply Orientation for $90^{0}$

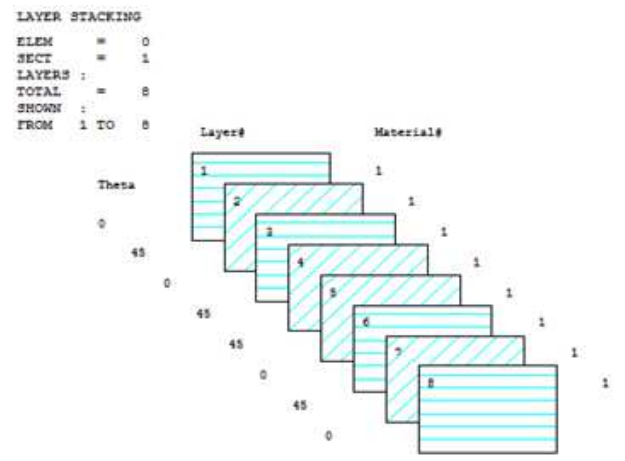

Figure 2: Ply Orientation for $\mathbf{4 5}^{\circ}$

Mesh with loads and Deformed Shape: The following figures 3and 4 represents mesh model, applying loads and deformed shape of the body in case I, 

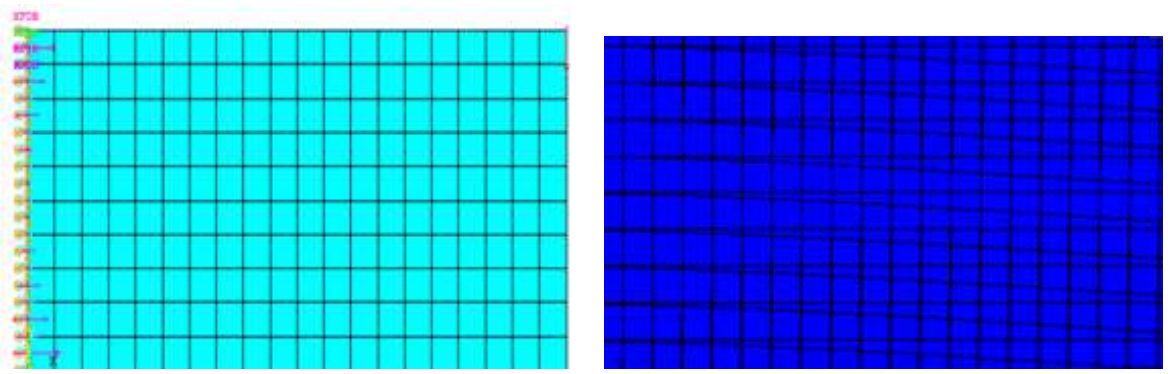

Figure 3: Appling Loads and Deformed Shape in Case-I
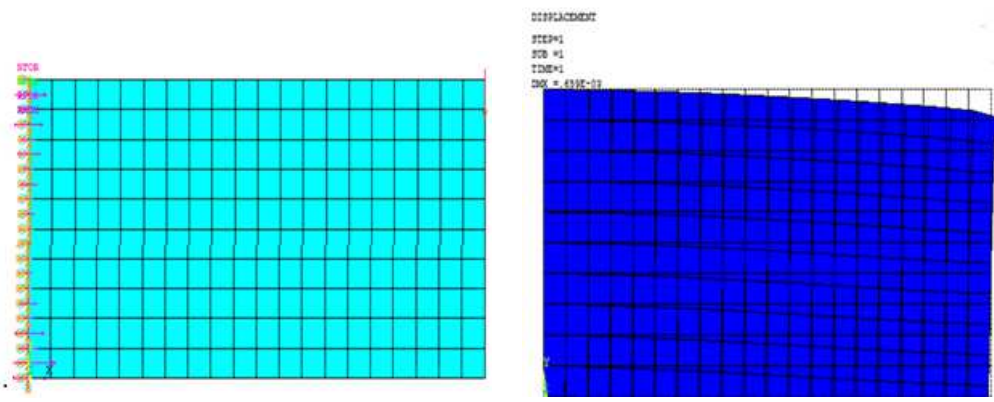

Figure 4: Appling Loads and Deformed Shape in Case-II

\section{RESULTS AND DISCUSSIONS}
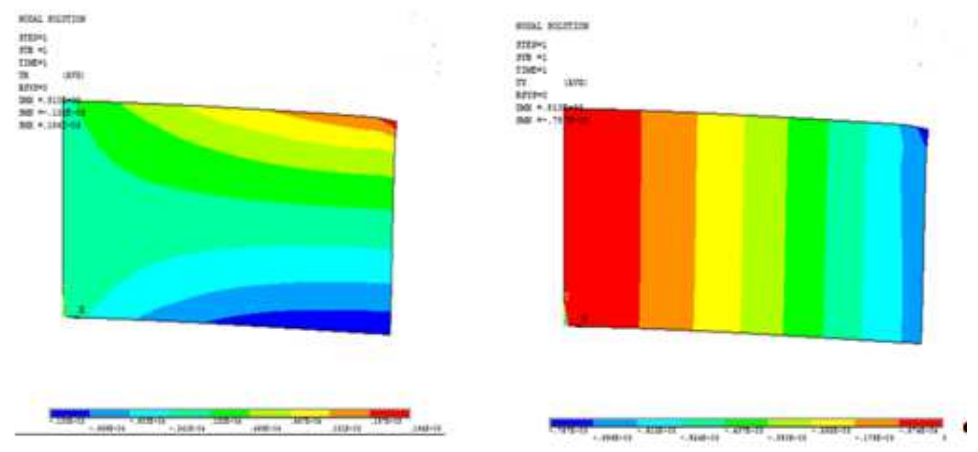

Figure 5: Nodal Solution in X and Y Displacement Case-I
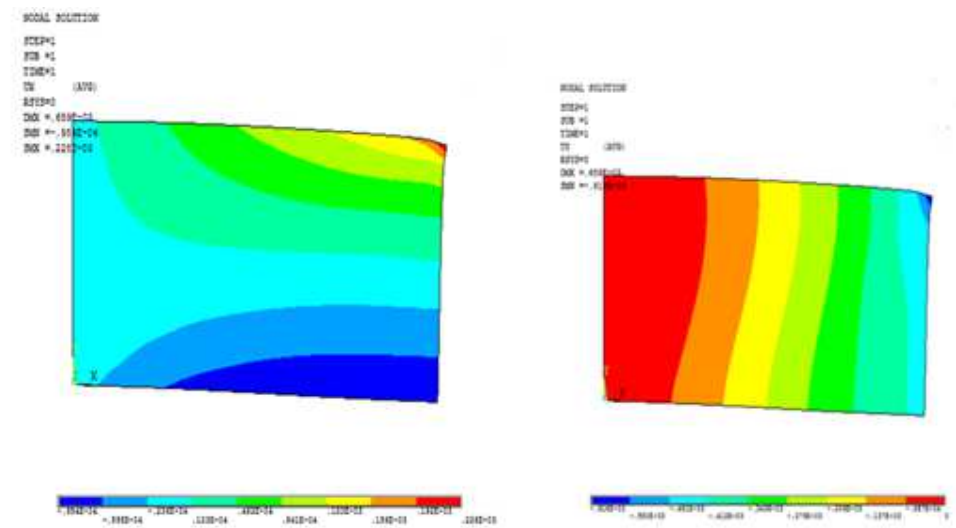


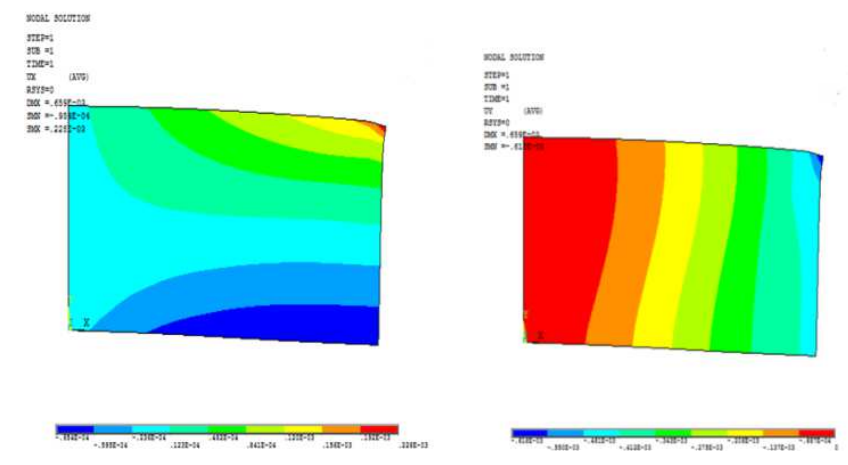

Figure 6: Nodal Solution $\mathrm{X}$ and $\mathrm{Y}$ Displacement in Case-II

By comparing Case-I and Case-II, in Case-II, we obtain the better displacement than Case-I
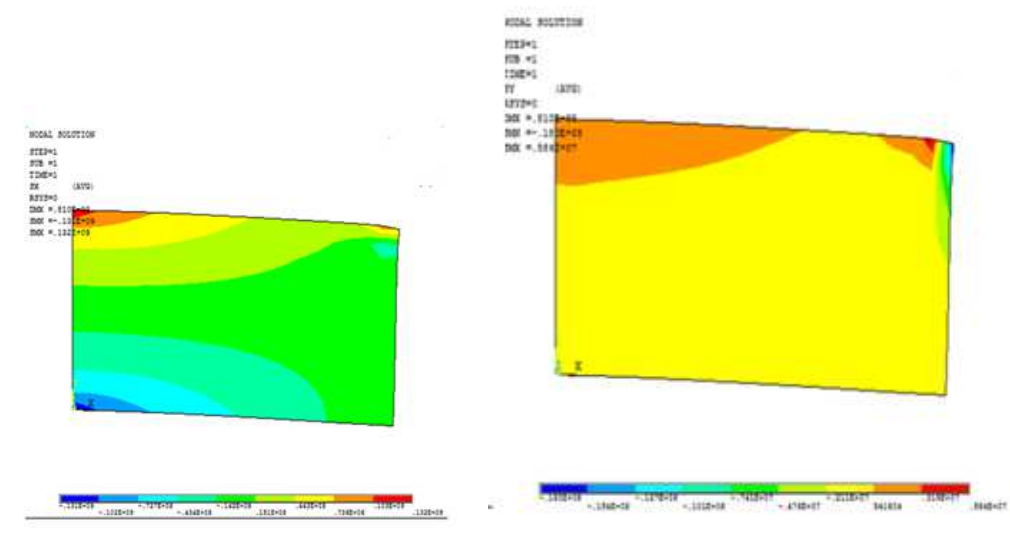

Figure 7: Stresses in X-direction and Y-direction in case-i
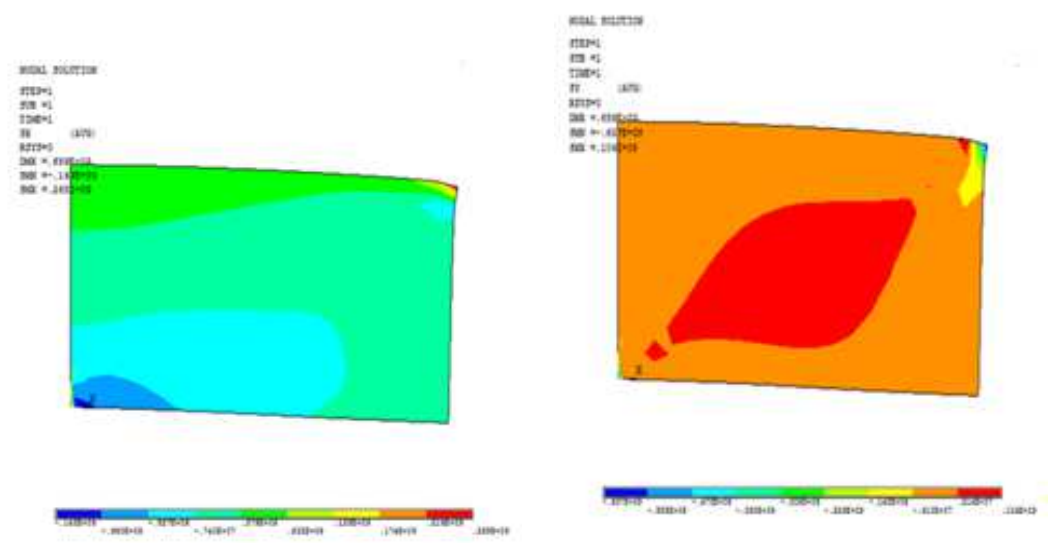

Figure 8: Stresses in X-Direction and Y-Direction in Case-ii

By comparing the above case stresses, in case-I got better result. 

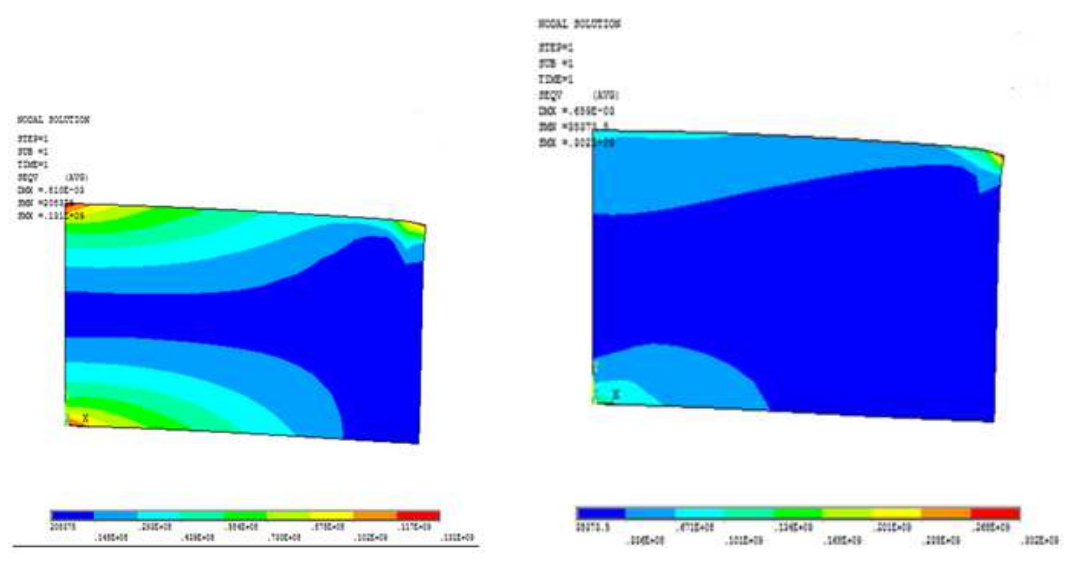

Figure 9: Von Mises Stresses in Case-I and Case-II

By observing the above figures, we find out that 45 degrees orientation is better than 90 degrees orientation. Actually, cross play laminate has more strength than unidirectional laminate. 45 degrees oriented laminate gives less deflection and more von misses stress than 90 degrees.

Hence, 45 degrees oriented laminate has more strength than 90 degrees laminated graphite epoxy composite

\section{CONCLUSIONS}

The Structural analysis on a composite laminate with different orientations has been done by considering the technical data and all the conditions, by using ANSYS for the study of various parameters like DOF, stress on $\mathrm{x}, \mathrm{y}$ and von mises stress. All these simulations are done by the application of finite element analysis by allowing us to perform every kind of simulation in ANSYS software, where we obtain the results by simulating in computational way. In earlier days, we used to do the same simulations theoretically and experimentally, for testing a particular model by investing a lot of time and money for obtaining its safe working conditions by performing crash tests after manufacturing the design model. But in this case, we can easily check out by simulating it on ANSYS software, by varying all the design parameters which allow us to change or improve any design, where ever it is prone to fail or damage on the computer itself, before it comes out as a testing model, saving the whole time and capital for manufacturing it. The usage of this module for the modeling and analysis of any type of test cases can be done in almost negligible time for any kind of design improvements. The values obtained by this software are also compared with the theoretical values at the corresponding locations.

From this, it can be concluded that, all simulations having any type of analysis systems can depend on this software ANSYS, which obtain results by using finite element method.

\section{REFERENCES}

1) K. Sreelakshmi "analysis of interlaminar stresses in a composite material with a circular hole by using finite element method" International Journal of Civil Engineering and Technology (IJCIET) Volume 8, Issue 5, May 2017, pp. 500-508,

2) G. Dhanajayan, Veeranjaneyulu Kalavagunta, V. Vamshi "Environmental Study on GFRP Composite Laminates", International Journal of Mechanical Engineering and Technology (IJMET) Volume 8, Issue 6, June 2017, pp. 480-493

3) N Madhavi K Sreelakshmi Dr. M. Satyanarayana Gupta "Ply Orientation on Failure of Composites" International Journal of Civil Engineering and Technology (IJCIET) Volume 8, Issue 5, May 2017, pp. 409-417 
4) G. S. Vivek et al.,, Vibration Analysis of Composite Laminated Plates Using Higher Order Theory and Levy's Solution, International Journal of Mechanical and Production Engineering Research and Development (IJMPERD), Volume 7, Issue 5, September-October 2017, pp. 51-62

5) N Madhavi, B Niharika M. Satyanarayana Gupta" Evaluation of ply Orientation on Failure of Kevlar 149 Epoxy" International Journal of Civil Engineering and Technology (IJCIET) Volume 8, Issue 5, May 2017, pp. Available online at http://www.iaeme.com/IJCIET/issues. ISSN Print: 0976-6308 and ISSN Online: 0976 @ IAEME Publication

6) https://en.wikipedia.org/wiki/Finite_element_method 